\title{
Accelerating dynamic imaging of the lung using blind compressed sensing
}

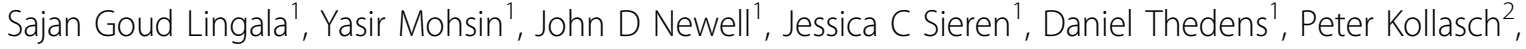 \\ Mathews Jacob ${ }^{*}$
}

From 17th Annual SCMR Scientific Sessions

New Orleans, LA, USA. 16-19 January 2014

\section{Background}

Real time dynamic lung MRI is a promising tool to noninvasively assess lung function and mechanics. However, it potential is not realized in the clinic due to the restricted spatio-temporal resolution and volume coverage. The main focus of this work is to overcome these drawbacks using the recent blind compressed sensing (BCS) scheme [Lingala et al., IEEE TMI 2013], which enables recovery from undersampled $\mathrm{k}-\mathrm{t}$ measurements.

\section{Methods}

The BCS scheme exploits the sparsity of the dynamic dataset in a learned dictionary, which is estimated from undersampled measurements. Since the non-orthogonal basis functions are learnt from the data, they offer more compact representations than conventional compressed sensing (CS) schemes [Otazo et al MRM 2010] that utilize predetermined dictionaries and conventional low rank models [Lingala et al., IEEE TMI 2011] that utilize few orthogonal learned bases. We test the feasibility of the proposed scheme by recovering a retrospectively undersampled 2D free breathing lung MRI dataset using BCS. The data from a single coronal slice was acquired on an anesthetized swine using a TrueFISP sequence $(\mathrm{TR}=138.62 \mathrm{msec}, \mathrm{TE}=1.06 \mathrm{msec}$, phase encoding steps: 128 , Image matrix size after interpolation: $256 \times 256$, FOV $320 \mathrm{~mm} 2$, GRAPPA factor: 3 ) on a $3 \mathrm{~T}$ Siemens Trio with a 12 channel coil. The 28 second

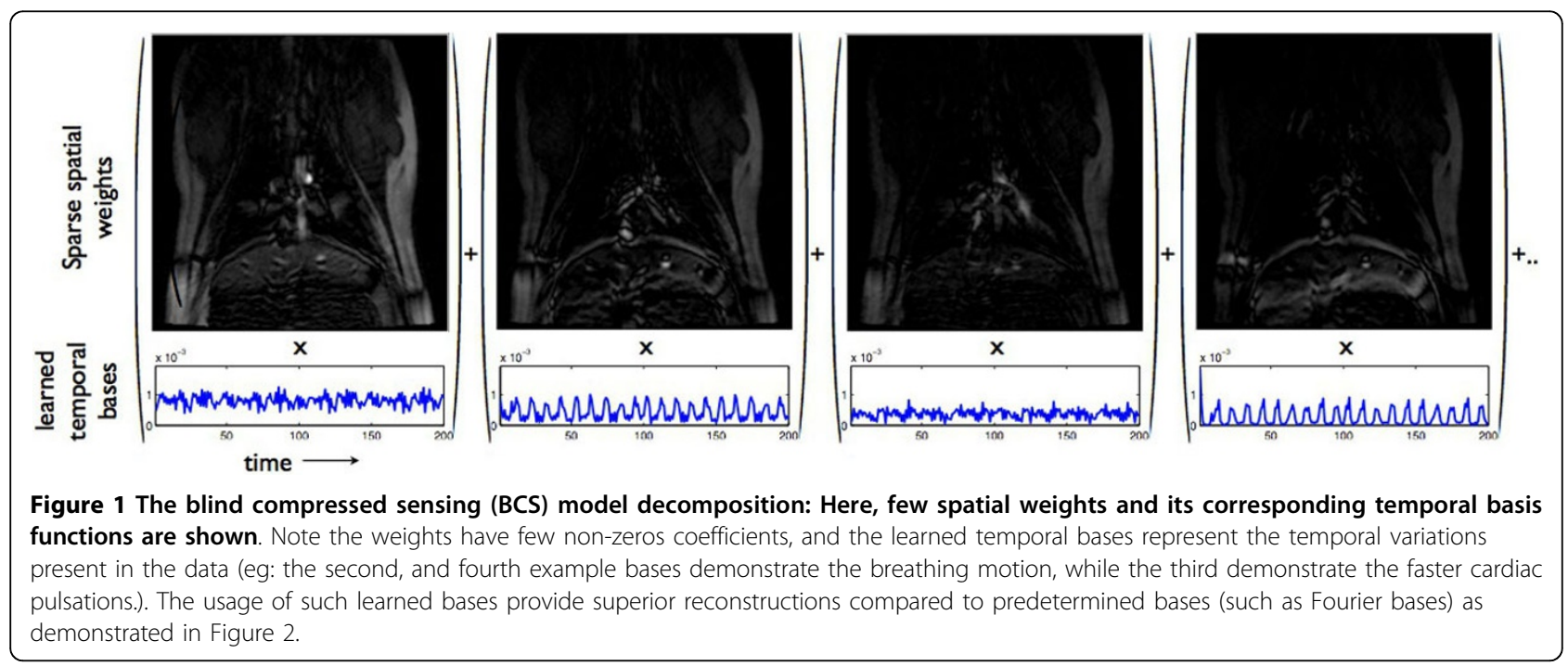

The University of lowa, lowa city, lowa, USA

Full list of author information is available at the end of the article 
acquisition resulted in $2002 \mathrm{D}$ images with a temporal footprint of $\sim 140$ msecs/image. The reconstructed images were retrospectively undersampled using a radial k-t sampling pattern, whose spokes were uniformly distributed in a single frame. The pattern was rotated by random angles in subsequent frames to ensure incoherence. Subsampling was performed by considering 40 to 10 spokes/frame. Image reconstruction was performed by the BCS, $\mathrm{k}-\mathrm{t}$ FOCUSS (CS using Fourier bases), and the low rank schemes.

\section{Results}

The BCS scheme provided superior spatio-temporal fidelity than CS and low rank methods. The CS scheme was found to be sensitive to motion artifacts, while the low rank reconstructions suffered from spatio-temporal blurring. Feasible subsampling levels upto 25 spokes/ frame where the mean square error was within 0.1 percent was achieved with the BCS scheme.

\section{Conclusions}

The blind compressed sensing scheme utilizing learned dictionaries has potential to accelerate free breathing dynamic lung MRI. The preliminary results in this work demonstrated high fidelity reconstructions of the BCS scheme in comparison to existing compressed sensing and low rank models. Further validation on patients is required to evaluate the clinical utility.

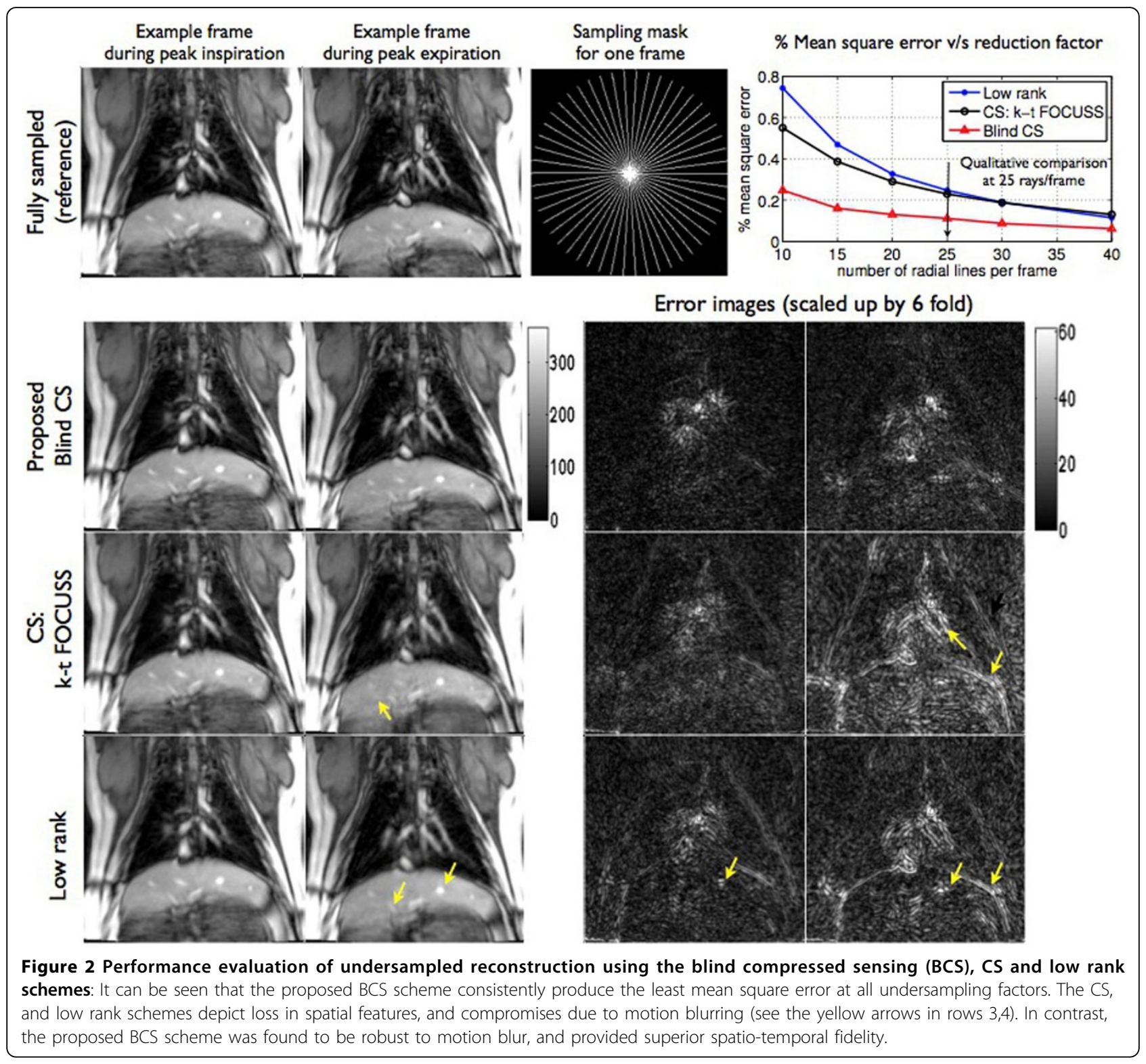




\section{Funding}

Grants from NSF CCF-0844812, NSF CCF-1116067, NIH 1R21HL109710-01A1, and AHA 12 PRE11920052.

\section{Authors' details}

${ }^{1}$ The University of lowa, lowa city, lowa, USA. ${ }^{2}$ Siemens Medical Solutions, Minneapolis, Minnesota, USA.

Published: 16 January 2014

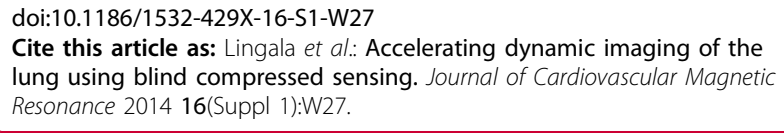

Submit your next manuscript to BioMed Central and take full advantage of:

- Convenient online submission

- Thorough peer review

- No space constraints or color figure charges

- Immediate publication on acceptance

- Inclusion in PubMed, CAS, Scopus and Google Scholar

- Research which is freely available for redistribution

Submit your manuscript at www.biomedcentral.com/submit
C Biomed Central 